\title{
Pigment Studies in the Genus Vaucheria
}

\author{
by R. CAubergs and JAN De GREeF*
}

Received January 20, 1971

\begin{abstract}
Vegetative thalli of Vaucheria dichotoma and Vaucheria geminata were studied for their pigment content.

Chromatography and spectral absorption characteristics of the pigments from those 2 species revealed the presence of chlorophyll $c$ as a minor fraction, in addition to chlorophyll a, $\beta$-carotene and 3 xanthophylls.

The fact of the presence of chlorophyll $c$ in the genus Vaucheria offers a useful clue for discussing its systematic relationship.
\end{abstract}

The taxonomic position and the phylogenetic relationships of the genus Vaucheria have been much discussed. Whether one is considering the general morphology of this genus, its detailed cytology, the ultrastructure of the individual organelles, its way of reproduction, its chemical cell contents, or its pigment composition, there are always diagnostic features which do raise points of difficulty to give it with certainty a real taxonomic status.

In the past it has been placed in the Siphonales (Chlorophyceae, Euphycophyta) ${ }^{1)}$. After it was found that several biochemical parameters were in contradiction with this point of view, its systematic position was revised.

Its cell walls do not contain native or mercerized cellulose as in other members of the Chlorophyceae, whilst the discoid chloroplasts, which lack pyrenoids, have an excess of $\beta$-carotene and starch is replaced by oil as the normal food storage material $^{2-4)}$. Nevertheless Dangeard ${ }^{5)}$ and Descomps ${ }^{6)}$ claim the presence of pyrenoids in some Vaucheria species, although these structures seem to be questionable. Also the chemical nature of the major cell wall constituents gives cause for doubts ${ }^{7)}$. Analysis of the photosynthetic pigments revealed similarities to the Xanthophyceae ${ }^{8)}$.

On the basis of these biochemical characteristics it was concluded that Vaucheria should belong to the Heterosiphonales (Xanthophyceae, Chrysophycophyta), which, so far as general morphology is concerned, bear much resemblance to chlorophycean groups. So far as reproduction is concerned Vaucheria presents anomalies whether placed in the Siphonales or Heterosiphonales. Sexual reproduction in most of the Xanthophyceae is isogamous, while there is a well-developed oogamy in Vaucheria. Depending upon the stage of the life cycle the motile cells of Vaucheria are isokont or heterokont ${ }^{9)}$. The flagella of the spermatozoids correspond with those of the Xanthophyceae, the flagella of the zoospores with those of the Chlorophyceae.

Considering the very heterogeneous features of Vaucheria, Maekawa ${ }^{10)}$ proposed the taxon Vaucheriophyta, a division between Chlorophyta and Chrysophyta.

In a recent investigation of the cytology and ultrastructure of a number of

* Laboratory of Plant Physiology, Rijksuniversitair Centrum Antwerpen, Groenenborgerlaan, 171, 2020 Antwerp, Belgium. 
species from several genera of Xanthophyceae, Hibberd and Leedale ${ }^{11)}$ separated a new class, the Eustigmatophyceae. This study clearly emphasizes the taxonomic difficulties in the Xanthophyceae and the problem of the whole concept of heterokont organization.

Studies on the pigment content of Vaucheria, however, are not convincing, neither conclusive, and show even more discrepancies. According to Seybold and Egle $^{12)}$ both chlorophylls $\mathrm{a}$ and $\mathrm{b}$ would be present in Vaucheria, while in further studies only chlorophyll a could be demonstrated ${ }^{8,13,14)}$.

In Vaucheria synandra and $V$. dichotoma two types of chlorophylls were found ${ }^{15)}$ : chlorophyll a and a "chlorophyll a like substance". Soma ${ }^{16)}$ showed that only at the zoospore stage there may exist "some other substance(s) different from chlorophyll a". Sagromsky ${ }^{17)}$ reexamined Soma's data and concluded that in zoospores phaeophytin a was present in addition to chlorophyll a.

The aim of the present work is to investigate the photosynthetic pigments of Vaucheria qualitatively and to work out this enigmatic problem with modern techniques.

\section{Materials and Methods}

Vaucheria species were collected from a natural stand. The plants were washed thoroughly in running tap water for several days to eliminate contaminating organisms. Only green thalli were selected for pigment analysis. The purity of the material was checked microscopically.

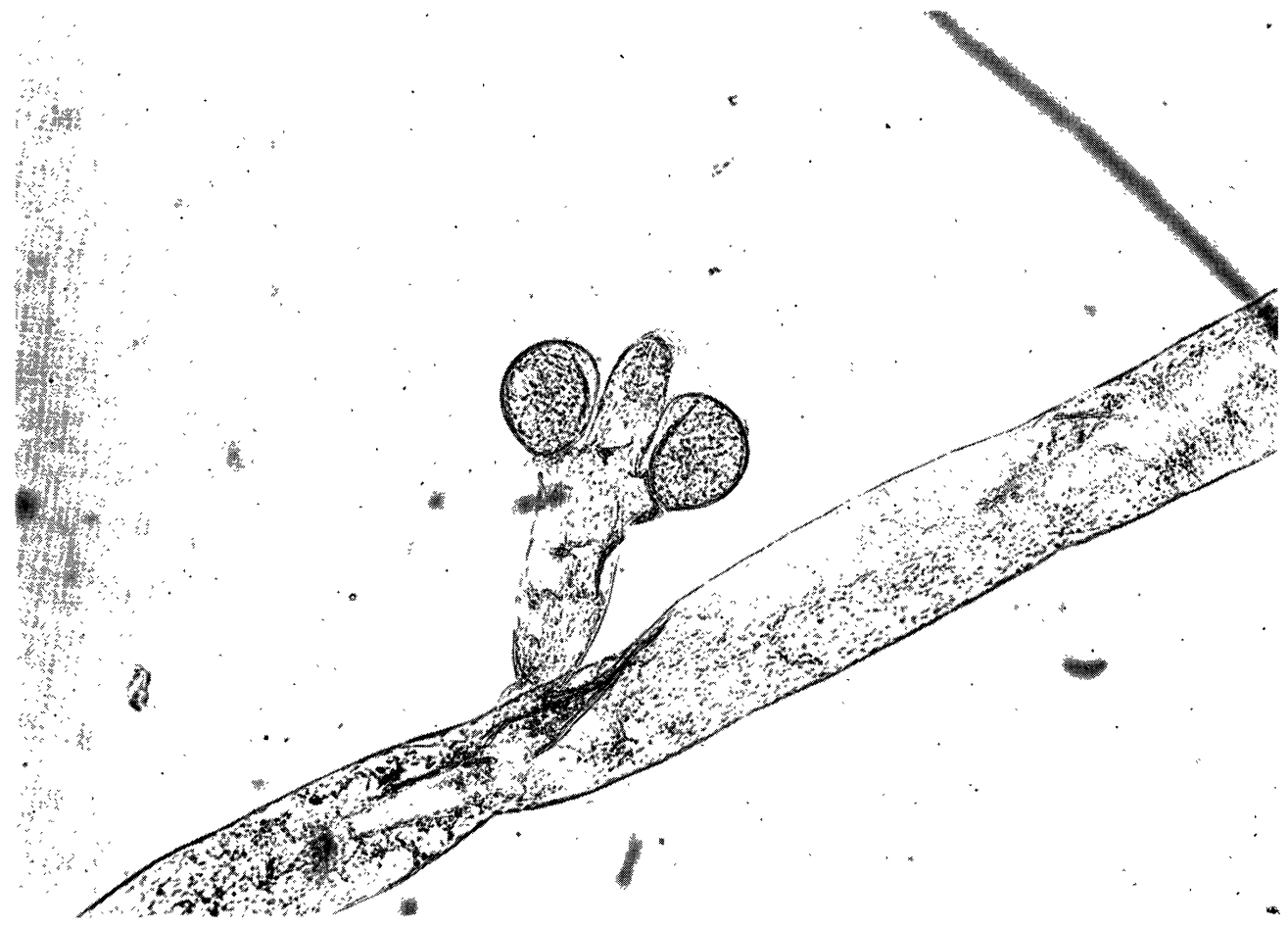

Fig. 1. Sex organs of Vaucheria geminata. 


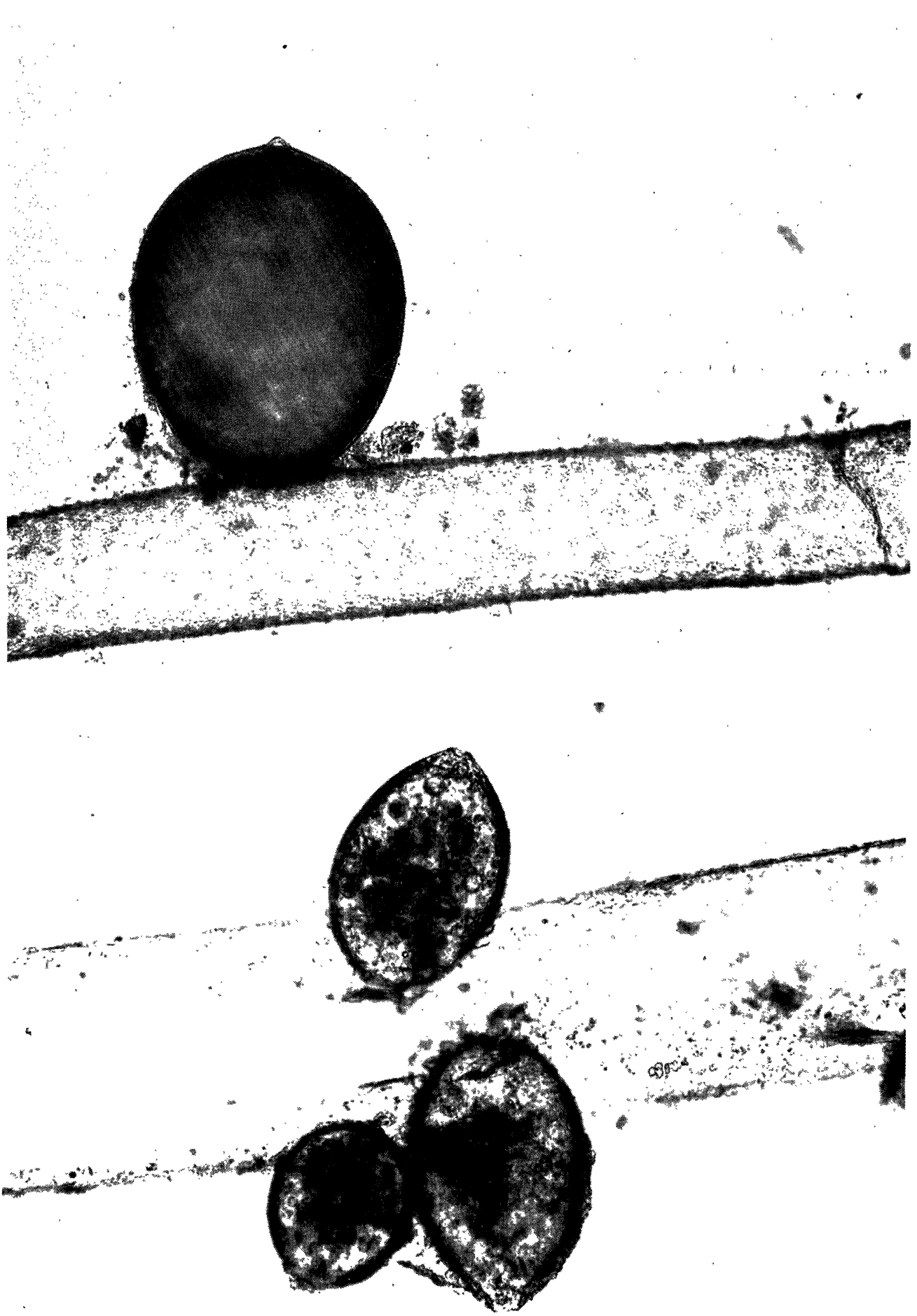

Fig. 2. Vaucheria dichotoma.

Upper: female filament with oogonium.

Lower: male filament with several antheridia. 
The pigments were extracted with light petroleum plus $2 \%$ methanol by mixing in a Waring blendor for $10 \mathrm{~min}$. During extraction the mixture was cooled with ice.

By centrifugating the cell débris were precipitated and discarded. The supernatant was passed through a column of starch $(3 \times 100 \mathrm{~cm})$. The column was washed with petroleum ether containing $50 \%$ benzene. In this way the pigments were roughly separated in a number of zones. Most of the chlorophyll c was absorbed on the upper part of the column. The large distance for washing the zones was very favorable for removing contaminating chlorophyll a in the trailing region of the chlorophyll c zone. After the different bands were dug out, the pigments of each zone were eluted in diethyl ether and concentrated under vacuum.

Further purification was carried out by thin layer chromatography. In order to characterize the pigment compounds several systems were chosen (Table 1). The use of various adsorbents with different activity grades and various mixtures of solvents of different polarity made it possible to obtain a successful separation of the applied substances.

For identification of chlorophyll $\mathrm{c}$ this pigment was prepared from the brown alga, Fucus vesiculosus, according to a modified method of Smith and Benite $z^{18)}$ The spectral properties of chlorophyll $c$ were then compared with the fraction isolated from the Vaucheria species.

Chopped thalli of Fucus were extracted two times with 1 liter methanol, each for 30 minutes. The methanol extracts were combined and treated with $200 \mathrm{~m} l$ of petroleum ether to remove most of the chlorophyll a.

A 2 liters portion of the methanolic solution was mixed with 1 liter diethyl ether and then shaken with 3 liters of saturated salt solution. The ether layer was removed and the aqueous alcohol layer extracted again with $800 \mathrm{ml}$ of ether. The combined ether extracts were washed two times with 1 liter of saturated salt solution and 1 liter of distilled water. The emulsion formed during each washing contained an interfacial precipitate, rich in chlorophyll c. The emulsion was removed separately and dissolved in methanol. The methanol solution was mixed with ether and then shaken with saturated salt solution. This treatment transferred the chlorophyll $\mathrm{c}$ to ether.

All the ether extracts were combined, concentrated under reduced pressure and further purified by rechromatography on cellulose MN 300 plates, as described above (System I). The pigments were eluted with chloroform, benzene or petroleum ether.

Absorption spectra of intact thalli and of the pigments solutions were measured with a Shimadzu MPL 50 recording spectrophotometer.

Table 1.

\begin{tabular}{|c|c|c|c|}
\hline System & Adsorbent & Solvent & Reference \\
\hline I & $\begin{array}{l}\text { cellulose ( } \mathrm{MN} 300) \text { impregnated } \\
\text { with paraffin }\end{array}$ & $\begin{array}{l}\text { paraffin-diethylether-acetone } \\
\quad(20: 20: 1)\end{array}$ & 26) \\
\hline II & $\begin{array}{l}\text { kieselguhr impregnated with } \\
\text { paraffin }\end{array}$ & acetone-methanol-water $(50: 47: 3)$ & 27) \\
\hline III & idem & acetone-methanol-water $(20: 76: 4)$ & 27) \\
\hline IV & cellulose & light petroleum- $\mathrm{CCl}_{4}(60: 40)$ & 28) \\
\hline $\mathrm{V}$ & kieselgel & $\begin{array}{l}\text { light petroleum-ethylacetate- } \\
\text { dimethylamine }(58: 30: 12)\end{array}$ & 29) \\
\hline
\end{tabular}




\section{Results}

Two species of the genus Vaucheria were used in this investigation, $V$. geminata (Fig. 1) and $V$. dichotoma (Fig. 2), as determined by means of their sex organs. Since the latter was abundantly found in the natural stand, most experiments were carried out with this organism.

From the absorption spectrum of thalli, measured in vivo (Fig. 3), it can only be concluded that chlorophyll $a$ is present, according to the long wavelength absorption maximum at about $678 \mathrm{~nm}^{19}$. The secondary and tertiary absorption bands of chlorophyll a are peaking higher, however, than normally would be expected. The absorption bands in the blue region reveal a mixture of several pigment components. After extraction of the pigments with light petroleum and $2 \%$ methanol, and chromatography on a starch column with the nonpolar solvent, benzene-light petroleum (1:1), several pigment zones were separated (Fig. 4a). We distinguished from bottom to top of the column: a light-yellow zone (fraction A), a yellow-orange band (fraction B), a concentrated, blue-green band (fraction C) and a pale, olive green band (fraction D). This last pigment zone of the column showed a very particular absorption spectrum, when eluted in ether (Fig. 5, A).

Next, each fraction was isolated, eluted.

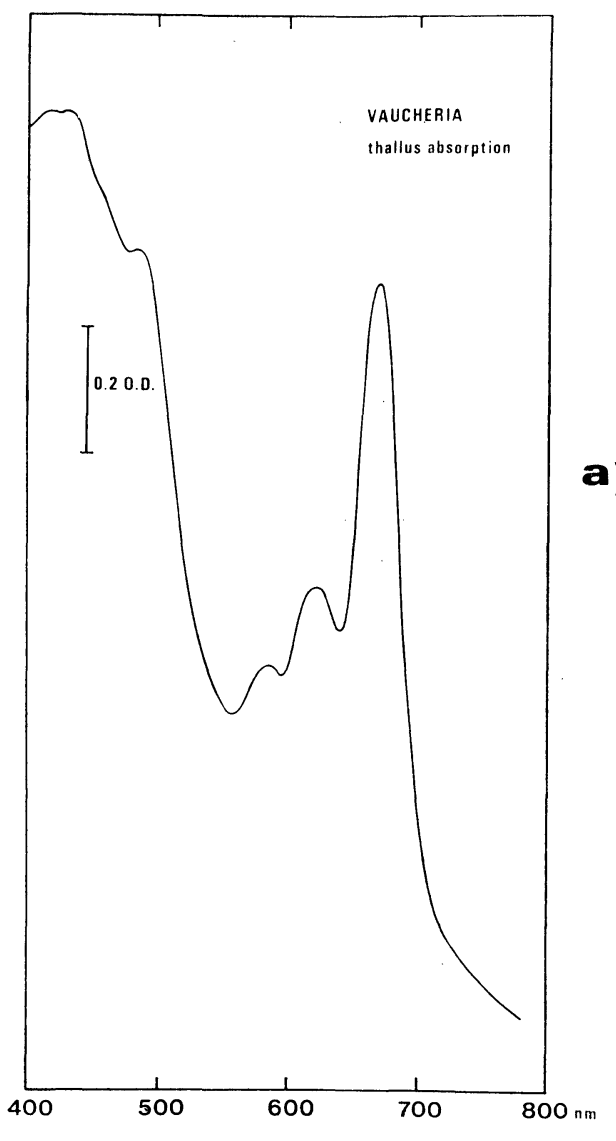

Fig. 3. in diethyl ether, concentrated and purified by thin layer chromatography (system I in Table 1). The results are shown in Fig. $4 \mathrm{~b}$. Fraction $\mathrm{C}$ was easily identified as chlorophyll a spectrophotometrically (Fig. 6). Fraction D, present as a very minor component, showed the spectral properties of chlorophyll $\mathrm{c}$ as compared to the standard preparation of chlorophyll c, obtained from Fucus vesiculosus (Figs. 5, B and 7). In fact

a)

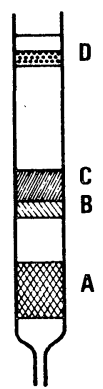

b)

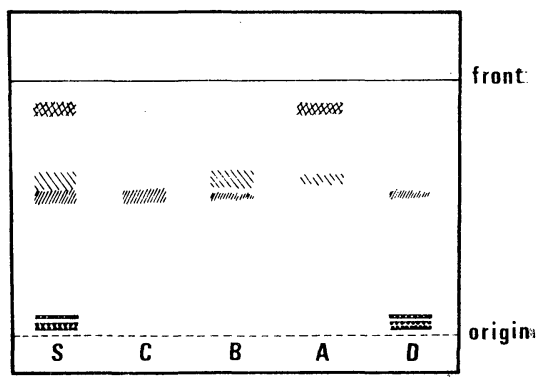

Fig. 4.

Fig. 3.7 Absorption spectrum (at $25^{\circ}$ ) of intact thalli.

Fig. 4. Chromatography of Vaucheria pigments.

a) Different zones after column chromatography.

b) Rechromatography on thin layer plates with. System I (further explanation: see results). 
we could observe two closely associated bands of chlorophyll $\mathrm{c}$ on the thin layer plates, but we were not able to separate them qualitatively fot absorption spectrophotometry.

In Fig. 8 we present the absorption curve of fractions $\mathrm{A}$ and $\mathrm{B}$. The identity of both yellow zones were tested for their polarity with different adsorbents and solvents (systems II, III and IV of Table 1). With systems II and III fraction A remained at the start line, while fraction $B$ moved with the solvent and was subfractionated in 2 or 3 spots. Using system IV fraction A moved with the front line, while fraction $B$ responded as an immobile spot. From this data we assumed that fraction A was one apolar substance, while fraction B has to be a more polar compound, being composed of several subfractions. The latter fraction was then chromatographied with system V. It spreads out in 3 bands. These components had very similar absorption curves (Fig. 9). We concluded that fraction A corresponds to $\beta$-carotene and that fraction $B$ is a mixture of 3 xanthophylls, regarding their chromatographic behavior and their spectral properties. In an analogous way we could prove the presence of chlorophyll $\mathrm{c}$ in Vaucheria geminata.

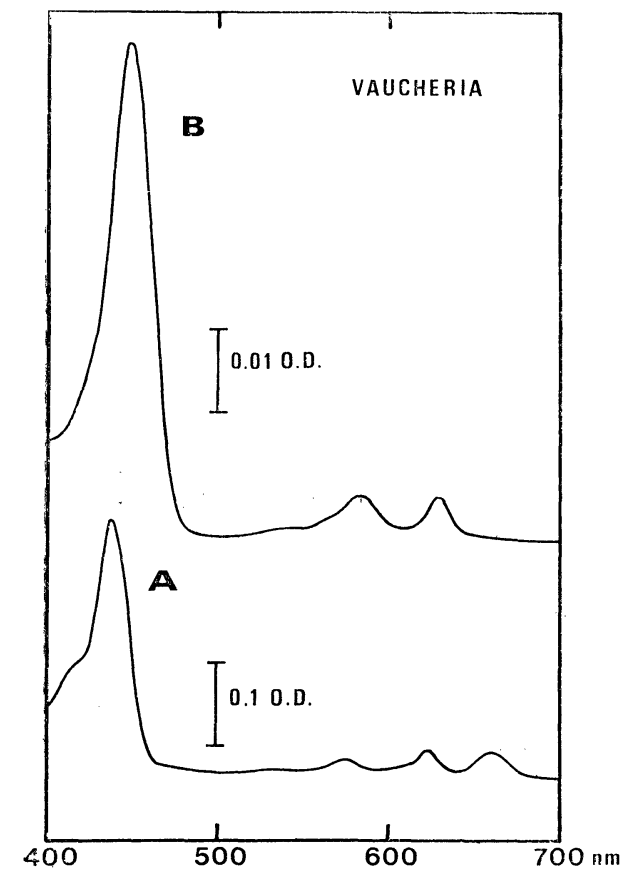

Fig. 5.

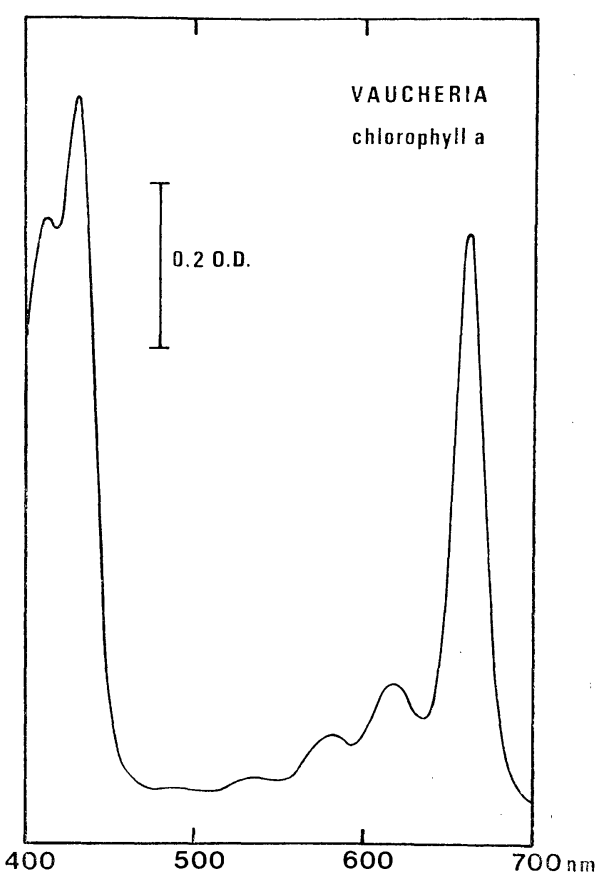

Fig. 6 .

Fig. 5. A. Absorption spectrum of the crude chlorophyll $\mathrm{c}$ fraction in diethyl ether after column chromatography.

B. Absorption spectrum of purified chlorophyll $c$ in diethyl ether. This was prepared from the crude fraction by rechromatography on thin layers of cellulose MN 300 , impregnated with paraffin and run in one dimension with paraffin-diethyl ether-acetone $(20: 20: 1 \mathrm{v} / \mathrm{v})$ as solvent.

Fig. 6. Absorption spectrum of purified chlorophyll a in chloroform. 


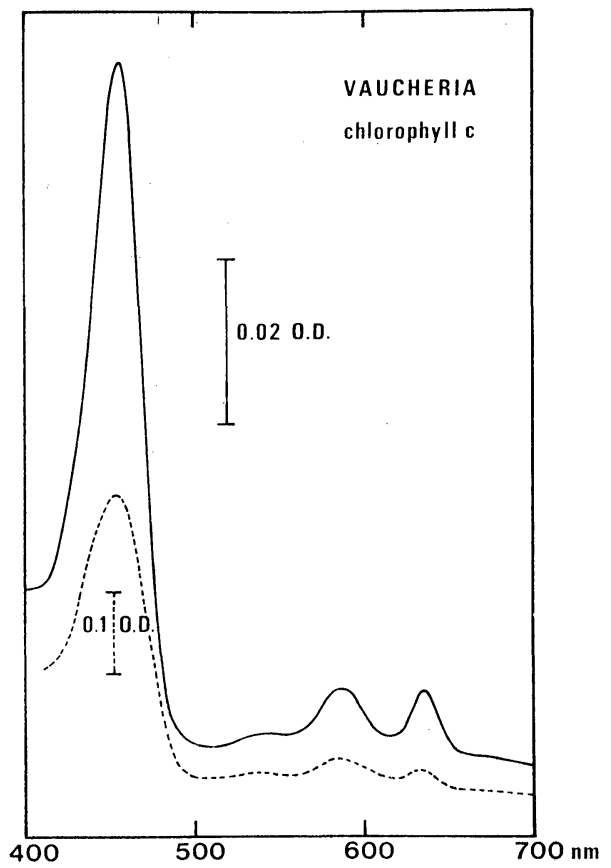

Fig. 7.

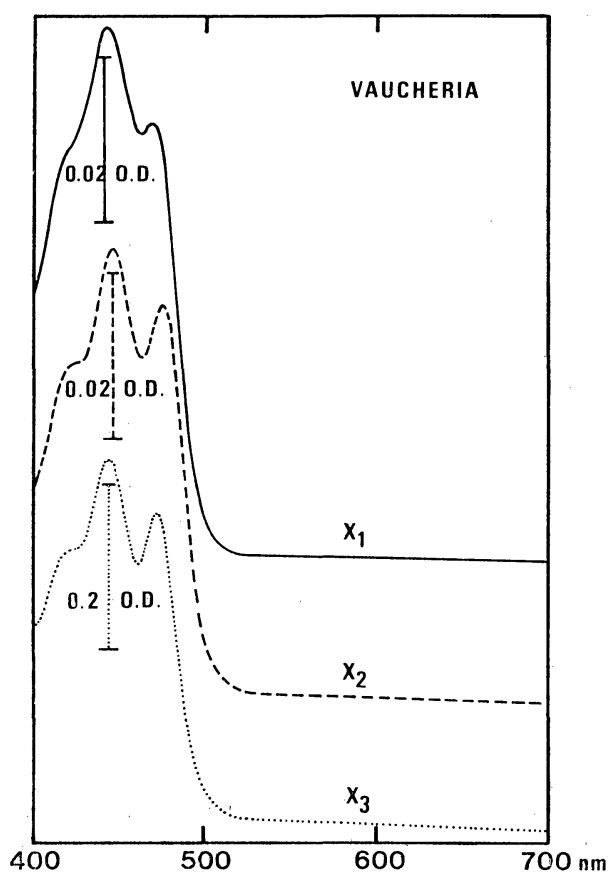

Fig. 9 .

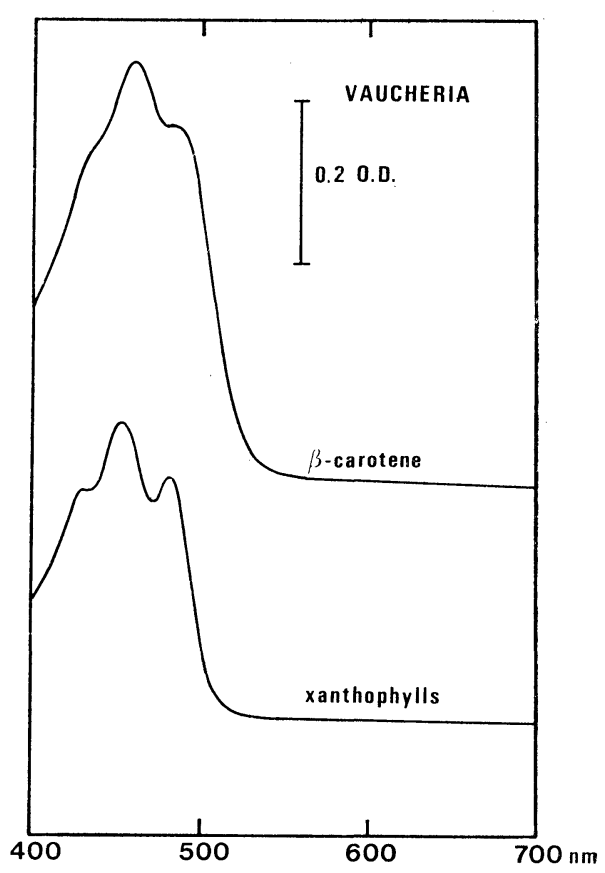

Fig. 8 .

Fig. 7. Absorption spectrum of purified chlorophyll c from Vaucheric(sclid line), compared to that of chlcrophyll c obtained from Fucus vesicul.osus (ciashed line). Chlcroform was used as solvent.

Fig. 8. Absorption spectra of $\beta$-carotene (Fraction A) and of the sum of all the xanthophylls (Fraction B) in chloroform after thin layer chromatography (System I).

Fig. 9. Absorption spectra of the 3 xanthophylls, separated from fraction $B$ with the use of System V. Solvent : ethanol. 


\section{Discussion}

From our results, based upon chromatography and spectral absorption curves, we conclude that in Vaucheria chlorophyll $\mathrm{c}$ is present in addition to chlorophyll a, $\beta$-carotene and 3 unknown xanthophylls.

The presence of chlorophyll $\mathrm{c}$ in the genus Vaucheria does raise another point of real taxonomic difficulty, necessitating a review of the whole concept of its phylogenetic position. Studies on the photosynthetic pigments of many kinds of plants indicate a remarkable constancy of pigment distribution amongst the members of the same phylogenetic group ${ }^{20-22)}$.

Therefore, chlorophylls are generally accepted as an excellent parameter for phylogenetic relationship. In this view Vaucheria cannot be held in the class Xanthophyceae. Our finding gives thus support to the many other anomalies, found in the genus Vaucheria as mentioned in the introduction. The fact, that many authors ${ }^{8,12-17)}$ did not succeed in isolating chlorophyll c from Vaucheria species, is primarily due to its scanty presence and to the difficulty for purifying this pigment from contaminating chlorophyll a. The crude fraction $\mathrm{D}$ obtained on the starch column was a "chlorophyll a like substance" as it was probably found by Sagromsky ${ }^{15)}$ and Soma ${ }^{16)}$ (Fig. 5, A).

Only by thoroughly washing the column over a large distance and by rechromatography on thin layer plates with appropriate solvents we could get rid of disturbing impurities.

The absorption maxima of the different pigments in Vaucheria (Table 2) are in good agreement with those reported in literature ${ }^{18)}$.

Analyzing the absorption curves of different chlorophyll c preparations, dissolved in ether, we observed small shifts in the absorption maxima. The ratios of the Soret $(445 \mathrm{~nm})$ to red $(629 \mathrm{~nm})$ bands also showed slight differences.

These variations can be explained by the fact that there exist 2 spectrally distinct components in preparations of chlorophyll $\mathrm{c}$ in Vaucheria. Indeed, on the thin layer plates, 2 light green zones with very similar Rf-values were present (see results). This interpretation is supported by the work of Jeffrey ${ }^{23)}$ who could separate 2 chlorophyll c components from Sargassum flavicans.

Table 2. Absorption maxima (in $\mathrm{nm}$ ) of Vaucheria pigments in different solvents.

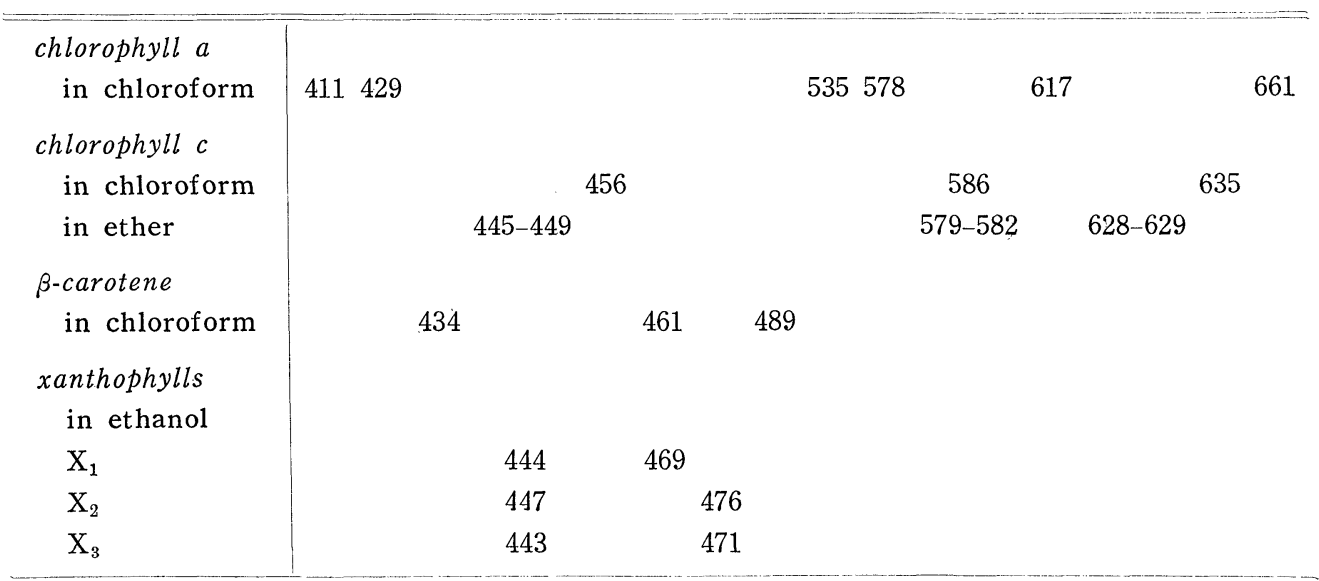


The 3 unidentified xanthophylls show absorption maxima very close to those found by Strain et $a l^{24)}$.

Comparing the ultrastructural organization of the plastids in Vaucheri $^{6)}$ with other chlorophyll c containing algae, e.g. Phaeophyta, Bacillariophyceae and Chrysophyceae ${ }^{25)}$ there is a striking similarity in their photosynthetic membrane arrangement: they are characterized by parallel series of 3 thylacoids. Hence, it would be very tempting to think that some chlorophyll form (c?) could act as a cementing agent in the partitions. However, some Xanthophyceae also have normal three-thylacoid lamellae ${ }^{11)}$.

We wish to thank Mrs. R. Vandecraen-Pype for her technical assistance through the course of this study.

\section{References}

1) Heering, W., Die Süsswasser-Flora Deutschlands, Oesterreichs und der Schweiz, p. 69 (Pascher, A., Ed., 1921).

2) Chadefaud, M., Bull. Soc. Bot. France 92: 47 (1945).

3) (1951).

4) Egerod, L.E., Univ. Calif. Publ. Bot. 25: 325 (1952).

5) Dangeard, P., Compt. Rend. Acad. Sc. Paris 205: 1429 (1937).

6) Descomps, S., Compt. Rend. Acad. Sc. Paris 256: 1333 (1963).

7) Maeda, M., Kuroda, K., Iriki, Y., Chihara, M., Nisizawa, K. and Miwa, T., Bot. Mag. Tokyo 79: 634 (1966).

8) Strain, H.H., Carneg. Inst. Washington Year Book 47: 97 (1948).

9) Koch, W. J., Elisha Mit. Sci. Soc. 67: 123 (1951).

10) Maekawa, F., Jour. Jap. Bot. 28: 105 (1.953).

11) Hibberd, D. J. and Leedale, G. F., Nature 225 : 758 (1970).

12) Seybold, A. und Egle, K., Planta 26: 491 (1937).

13) Montfort, C. und Küsters, G., Bot. Archiv. 40: 571 (1940).

14) Seybold, A., Egle, K. und Hülsbruch, W., Bot. Archiv. 42: 239 (1941).

15) Sagromsky, H., Zeitschr. Naturforschg. 12b: 684 (1957).

16) Soma, S., J. Fac. Sci. Tokyo $7: 535$ (1960).
17) Sagromsky, H., Ber. Deutsch. Bot. Ges. $75: 345$ (1962).

18) Smith, J.H.C. and Benitez, A., Modern Methods of Plant Analysis, p. 142 (Peach, K. and Tracey, M. V., Ed. Springer Verlag, Berlin 1955).

1.9) Shibata, K., J. Biochem. $44: 147$ (1957).

20) Allen, M. B., French, C.S. and Brown, J.S., Comparative Biochemistry of Photoreactive Systems, p. 33 (Allen, M. B., Ed., Academic Press, New York, 1960).

21) Holt, A. S., Chemistry and Biochemistry of Plant Pigments, p. 3 (Goodwin, T. W., Ed., Academic Press, London, 1965).

22) Strain, H.H., Biochemistry of Chloroplasts, Vol. I, p. 387 (Goodwin, T.W., Ed., Academic Press, New York, 1966).

23) Jeffrey, S. W., Nature 220: 1032 (1968).

24) Strain, H. H., Svec, W. A., Aitzetmüller, K., Grandolfo, M. and Katz, J. J., Phytochem. $7: 1417$ (1968).

25) Manton, I., Biochemistry of Chloroplasts Vol I, p. 23 (Goodwin, T. W. Ed., Academic Press, New York, 1966).

26) Randerath, K., Thin-layer Chromatography (Academic Press, New York, 1966).

27) Egger, K., Planta $58: 664$ (1962).

28) Chromatographie Symposium II, Brussel 1962, p. 75 (1965).

29) Riley, J. P. and Wilson, T. R. S., J. Mar. Biol. Assoc. U. K. 45 : 583 (1965). 